\title{
Can Prompt Endoscopic Vitrectomy in Post-Trauma Endophthalmitis with Corneal Edema Avoid Unnecessary Keratoplasties?
}

This article was published in the following Dove Press journal:

International Medical Case Reports Journal

\author{
Mohammad Abdul Khader (D) ${ }^{1,2}$ \\ Rajeev Reddy Pappuru' \\ Vivek Pravin Dave' \\ 'Smt. Kanuri Santhamma Center for \\ Vitreoretinal Diseases, LV Prasad Eye \\ Institute, Hyderabad, India; ${ }^{2}$ Academy for \\ Eye Care Education, LV Prasad Eye \\ Institute, Hyderabad, India
}

\begin{abstract}
Objective: To describe a series of prompt endoscopic vitrectomy in eyes with post-trauma endophthalmitis and hazy cornea.

Methods: Retrospective consecutive interventional case series. Cases of endophthalmitis with hazy cornea which underwent prompt endoscopic vitrectomy were analyzed. The study period was from August 2018 to April 2019. The final anatomic and functional outcomes are reported here.

Results: Four eyes of four patients were included. Mean age at presentation was 24.50 \pm 21.29 years (median 24 years). All cases were post-open globe injury. Microbiology showed smear positivity in $3 / 4(75 \%)$ and culture positivity in $2 / 4(50 \%)$. The antibiotic susceptibility was $100 \%$ for vancomycin and ceftazidime. Mean follow-up was 7.75 \pm 1.7 months (median 7.5 months). Favorable anatomic outcome was seen in $100 \%$ of cases and favorable functional outcome in $75 \%$ cases.
\end{abstract}

Conclusion: Endoscopic vitrectomy allows for early intervention in endophthalmitis post openglobe injuries. This enables early resolution of infection and avoids a need for unnecessary corneal interventions.

Keywords: endoscopy, keratoplasty, corneal opacity, endoscopic vitrectomy

\section{Introduction}

Endophthalmitis secondary to open-globe injury is one of the most devastating and vision-threatening complications. It accounts for $25-30 \%$ of cases of infectious endophthalmitis. ${ }^{1}$ Risk factors include presence of intraocular foreign body (IOFB), delayed wound closure, lens rupture, and trauma with contaminated objects. ${ }^{2,3}$ Grampositive cocci are the commonest causative organisms in post traumatic endophthalmitis however Bacillus spp., fungi and mixed infections are also reported. ${ }^{4,5}$ In endophthalmitis following open globe injury the surgical view is compromised due to corneal edema, keratitis and hyphema precluding the possibility of an adequate and effective vitrectomy. Ophthalmic endoscope helps overcome this difficulty and bypass the hazy anterior segment, thus allowing access to the vitreous cavity. ${ }^{6}$ In the current communication, we describe a series of cases of endophthalmitis following open-globe injury with hazy corneas, managed with prompt endoscopic vitrectomy.

\section{Methods}

Smt. Kanuri Santhamma Center for

Vitreoretinal Diseases, LV Prasad Eye

Institute, Hyderabad, India

Tel +9l-7680859900

Email vivekoperates@yahoo.co.in

\section{Study Design}

This was a retrospective consecutive interventional case series managed at a tertiary care center (LV Prasad Eye Institute, Hyderabad, India). All patients were Indians. 
Appropriate Institutional Review Board approval was given by the LV Prasad Eye Institute Ethics Committee. Medical records of all patients with endophthalmitis following open-globe injury who underwent prompt endoscopic vitrectomy between August 2018 and April 2019 were analyzed. All patients provided a written informed consent for the case details and images to be published. For underage patients, parents provided the written informed consent.

\section{Methodology}

All patients underwent primary globe repair followed by prompt endoscopic vitrectomy within 48-72 hours. Intravitreal vancomycin $(1 \mathrm{mg} / 0.1 \mathrm{~mL})$ (Ledovanc, Celon Laboratories, India) and ceftazidime $(2.25 \mathrm{mg} / \mathrm{mL})$ (Ceftaz, Cipla ltd, India) was administered to all patients at the first intervention. Injections were repeated after 48 hours based on the smear and culture report. Basic microbiological profile (Calcofluor white, Gram stain, Giemsa stain) and culture was taken from the vitreous samples. Based on the culture reports and clinical condition, the course of management and further interventions were decided by the treating physician. Anatomic and functional outcomes were evaluated at the last visit. A favorable anatomic outcome was defined as preservation of the globe, attached retina and absence of hypotony at the last visit. Favorable functional outcome was defined as BCVA $\geq 20 / 400$ at the last visit. ${ }^{7-9}$

\section{Technique of Endoscopy}

Endoscopy was done using the 20/23G endoscope (E2 Laser and Endoscopy System; EndoOptiks, Inc, Little Silver, NJ, USA) with light and video dual function. The E2 Ophthalmic Laser Endoscopy system console uniquely combines endoscopic imaging and laser treatment capability.

The console houses a high resolution video camera, 175 or 300 watt xenon light source and an $810 \mathrm{~nm}$ diode laser. The endoscope provides a wide field image allowing a panoramic intraocular view of the entire retina or a close up (down to $0.75 \mathrm{~mm}$ ) highly magnified view of the pathology. The in-built video adapter offers optimum and manual focus of the endoscopic image. The $810 \mathrm{~nm}$ laser filters are installed in all models and a $532 \mathrm{~nm}$ laser option is available. The resolution of the $20 \mathrm{G}$ camera is 10,000 pixels while that of the $23 \mathrm{G}$ camera is 6000 pixels. The surgical steps included sterile draping of the eye followed by creating two superior sclerotomies and one inferotemporal sclerotomy as per the surgeon's preference for a standard three port vitrectomy surgery. The endoscope was then maneuvered to the midpupillary retro-lental location and position confirmed on the television monitor. The vitrector was then furthered towards the endoscope to position it in the vitreous cavity. Vitrectomy was performed under endoscopic visualization. A thorough vitrectomy to the extent possible was attempted. The end point of surgery was taken as visibility of the disc and the retina. Wherever possible an attempt was made to induce posterior vitreous detachment (PVD). If a strong adherence was noted on the induction, PVD induction was avoided (Supplementary Video S1).

\section{Results}

Four eyes of four patients who were diagnosed as traumatic endophthalmitis and hazy corneas were managed with prompt endoscopic vitrectomy. Two males and two females were included in the study. Mean age at presentation was $24.50 \pm 21.29$ years (median 24 years) (Table 1). At presentation the vision varied from perception of light to counting fingers close to the face. Two eyes had hazy anterior segment media due to a repaired corneal tear and concurrent corneal edema, one eye had a repaired corneal tear with keratitis and one eye had dense corneal edema in the visual axis. Mean follow up was $7.75 \pm 1.7$ months (median 7.5 months). All cases showed resolution of corneal infection and edema in the follow-up period with near total corneal clarity. At the last follow up all patients had good anatomical outcome and three eyes $(75 \%)$ had good functional outcome (Figure 1). Three (75\%) samples showed smear positivity and two samples (50\%) showed culture positivity. Streptococcus pneumoniae and Enterobacter cloaceae were isolated from one patient sample each whereas two patient samples did not reveal any organism. Sensitivity for vancomycin and ceftazidime was $100 \%$. One patient has a concurrent traumatic cataract and required lensectomy. The patients where the isolation was Streptococcus pneumoniae and Enterobacter cloaceae received silicone oil injection in view of the anti-microbial properties of silicone oil. ${ }^{10}$

\section{Patient I}

This was a 10-year-old female with history of injury to the right eye with a wire a week previously. The patient was diagnosed to have a corneal tear elsewhere and subsequently underwent a corneal tear repair. At the visit to our clinic, the presenting vision was hand motions close to face. Anterior segment showed hypopyon with aphakia (from the previous surgery) and exudates in the vitreous cavity. The patient underwent a vitreous biopsy initially 
Table I Demographic and Clinical Data of Cases with Traumatic Endophthalmitis and Opaque Cornea

\begin{tabular}{|c|c|c|c|c|}
\hline S. No & I & 2 & 3 & 4 \\
\hline Gender & $\mathrm{F}$ & M & M & $\mathrm{F}$ \\
\hline Age (years) & 10 & 38 & 47 & 3 \\
\hline Visual acuity at presentation & $\mathrm{HM}$ & CFCF & PL & Not fixating to light \\
\hline Anterior chamber findings & Hypopyon & No view & Fibrin and cells & Hypopyon \\
\hline $\begin{array}{l}\text { Interval between start of symptoms } \\
\text { and presentation }\end{array}$ & I day & I day & 4 days & 4 days \\
\hline Cause of poor visualization & $\begin{array}{l}\text { Repaired corneal tear } \\
\text { with edema }\end{array}$ & $\begin{array}{l}\text { Repaired corneal tear } \\
\text { with edema }\end{array}$ & $\begin{array}{l}\text { Repaired corneal tear } \\
\text { with edema }\end{array}$ & $\begin{array}{l}\text { Stromal edema in the visual } \\
\text { axis with edema }\end{array}$ \\
\hline Procedure performed & $\begin{array}{l}\text { Endoscopic PPV+SOI } \\
+I O A B\end{array}$ & $\begin{array}{l}\text { Endoscopic PPV } \\
+ \text { IOAB }\end{array}$ & $\begin{array}{l}\text { Endoscopic PPV+PPL } \\
+I O A B\end{array}$ & $\begin{array}{l}\text { Endoscopic PPV +EL+SOI } \\
+ \text { IOAB }\end{array}$ \\
\hline Smear & Gram positive bacilli & Gram positive cocci & No organism & Gram positive cocci \\
\hline Culture & Enterobacter cloacae & No organism & No organism & Streptococcus pneumoniae \\
\hline Follow up (months) & 7 & 8 & 10 & 6 \\
\hline $\begin{array}{l}\text { Total no of interventions including } \\
\text { IOAB }\end{array}$ & 5 & 6 & 4 & 3 \\
\hline Final visual acuity & $20 / 40$ & $20 / 100$ & $20 / 500$ & $\begin{array}{l}\text { Following objects at } 3 \text { meter } \\
\text { distance }\end{array}$ \\
\hline Final anatomic outcome & Favorable & Favorable & Favorable & Favorable \\
\hline Final visual outcome & Favorable & Favorable & Unfavorable & NA \\
\hline Cause of final low vision (if any) & Corneal scar & Secondary glaucoma & Corneal scar & Corneal scar \\
\hline Further visual potential & $Y$ & $Y$ & $Y$ & NA \\
\hline
\end{tabular}

Abbreviations: PPV, pars plana vitrectomy; PPL, pars plana lensectomy; SOI, silicone oil injection; IOAB, intraocular antibiotic; EL, endolaser.

which at 48 hours showed a growth of Enterobacter cloacae. Following this the patient underwent a prompt endoscopic vitrectomy with intraocular antibiotic injection and silicone oil injection. At the last follow up 5 months postoperative, the endophthalmitis had resolved with a final best corrected visual acuity of 20/40.

\section{Patient 2}

This was a 38 -year-old male with a history of injury to the right eye with a stick a week earlier. The patient was diagnosed to have a corneal tear elsewhere and underwent a corneal tear repair. At the visit to our clinic, the presenting vision was counting fingers close to face. Anterior segment showed no view due to exudates and B scan confirmed exudates in the vitreous cavity. The patient underwent a prompt endoscopic vitrectomy with intraocular antibiotic injection. At the last follow up 8 month post- operative, the endophthalmitis had resolved with a final best corrected visual acuity of 20/100. The patient developed secondary glaucoma which was controlled with topical anti-glaucoma medications.

\section{Patient 3}

The third patient was a 47-year-old male with history of injury to the left eye with a stone. The patient was diagnosed to have a corneal tear elsewhere and subsequently underwent a corneal tear repair locally. At the visit to our clinic, the presenting vision was only perception of light. Anterior segment showed intense fibrin reaction with no view of the posterior segment. B scan ultrasound showed exudates in the vitreous cavity consistent with the diagnosis of endophthalmitis. The patient underwent a prompt endoscopic vitrectomy with intraocular antibiotic injection. At the last follow up 10 months post-operative, the 


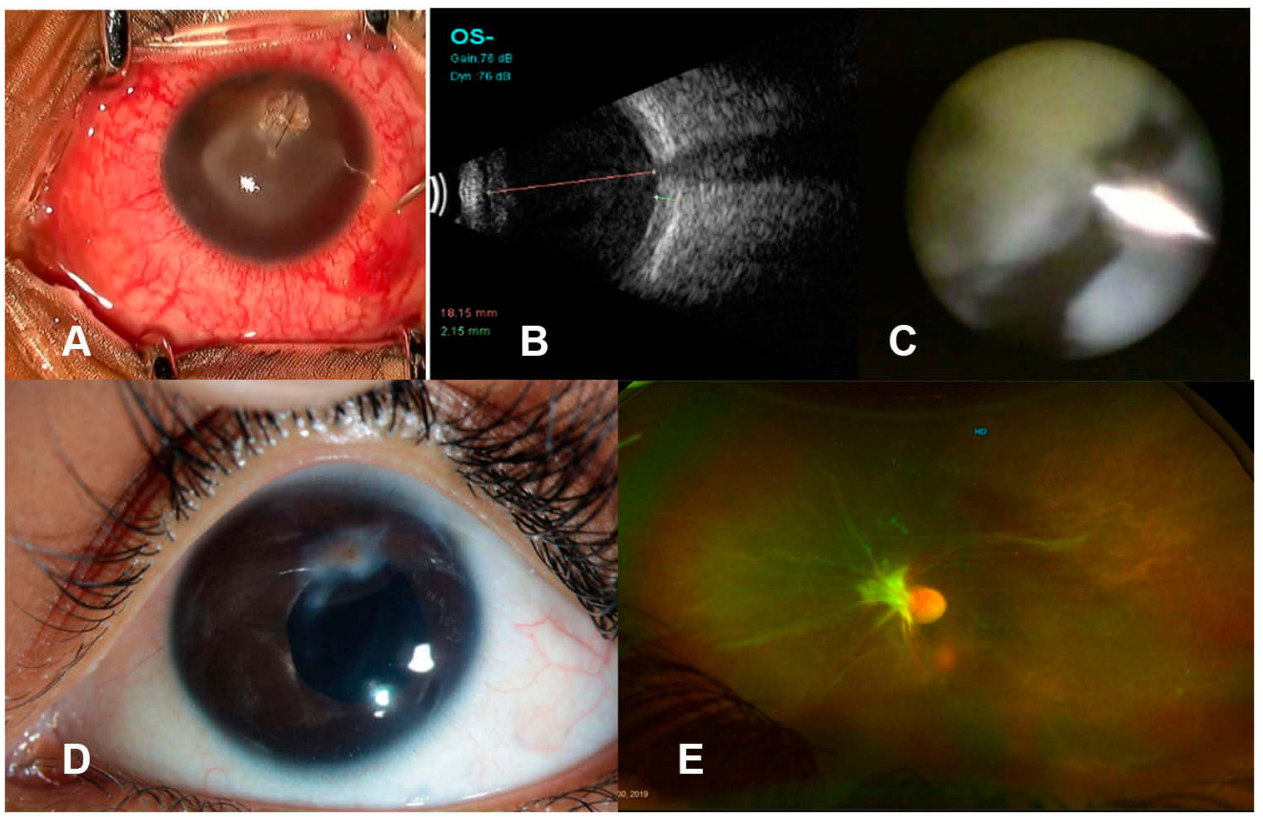

Figure I (A) External photo showing repaired corneal tear with infiltrate causing corneal opacity. (B) B scan ultrasound showing vitreous cavity filled with echoes suggestive of endophthalmitis. (C) Endoscopic photo showing vitreous cutter clearing the dense exudates. (D) Slit lamp photo at 3-month follow-up visit showing resolved infiltrate and clear cornea. (E) Fundus photo at 3-month follow-up visit showing attached retina with resolved inflammation in the vitreous cavity.

endophthalmitis had resolved with a final best corrected visual acuity of $20 / 500$.

\section{Patient 4}

This was a 3-year-old female with history of injury to the left eye with a nail 6 days ago. At the visit to our clinic, the patient was not fixating at the light source. Cornea was edematous with a self-sealed puncture wound paracentrally. Anterior segment showed hypopyon and exudates were noted in the vitreous cavity on B scan ultrasound. The patient underwent a vitreous biopsy initially which at 48 hours showed a growth of Streptococcus pneumoniae. Following this the patient underwent a prompt endoscopic vitrectomy with intraocular antibiotic injection and silicone oil injection. Two iatrogenic breaks occurred during surgery that underwent endolaser. At the last follow up 6 months post-operative, the endophthalmitis had resolved with a final best corrected visual acuity of counting fingers at 3 meters.

\section{Discussion}

The current series demonstrates the application of prompt endoscopic vitrectomy to debulk the vitreous in cases of endophthalmitis following open-globe injuries in the presence of concurrent hazy anterior segment media. Endoscopic approach has advantages over the conventional viewing system. Unlike the conventional viewing system, endoscopic set up gives pristine clarity of view even in the presence of significant or total media opacities. It can by-pass opaque corneas completely to give a view of the retina and help ascertain the pathology in the posterior segment. The retina and intraocular structures can be reached closely to give a highly proximal view of the structures of interest. This helps in better assessment of the disease. Thorpe ${ }^{11}$ first introduced ophthalmic endoscope for removal of intraocular foreign bodies. It was later employed for various procedures like ciliary body ablation and endophotocoagulation. ${ }^{12,13}$ Previous studies have described the role of endoscopic vitrectomy in endophthalmitis. ${ }^{14}$ Our group recently reported the outcomes of endoscopic vitrectomy in 33 cases of endophthalmitis. ${ }^{15}$

Using a temporary keratoprosthesis for visualization during vitrectomy, followed by immediate penetrating keratoplasty is also described for treating endophthalmitis with opaque media but such an approach would lead to multiple interventions and investment of time and energy. ${ }^{16}$ However the anatomic and visual outcomes using endoscopy and temporary keratoprosthesis are comparable. ${ }^{17}$ In addition endoscopy has the advantage of fewer interventions and earlier diagnosis.

In our case series, patients underwent endoscopic vitrectomy due to hazy anterior segment. Three patients had repaired corneal tear in the visual axis with surrounding edema, one patient had a sutured corneal tear at 12 O'clock with diffuse edema which obscured the view to the posterior 
segment. Following vitrectomy, patients only underwent a repeat intraocular antibiotics (IOAB) if recommended by the physician, the number and frequency were based on the clinical condition and physicians' discretion. Corneal edema, which necessitated the use of endoscopy decreased after resolution of infection thus improving visual outcome. With a conventional approach, these patients would have to be managed by means of a temporary keratoprosthesis and then would need penetrating keratoplasty. Such an approach would make the patients obligatory post-keratoplasty patients with all the associated requirements of graft care and a life-long risk of graft rejection. Endoscopic approach in this series allowed an opportunity for these eyes to have a natural resolution of the corneal edema and infiltrate, helping to preserve the native cornea and avoid graft-related sequelae.

In the current series all the patients had good anatomical and fair visual outcome. This is despite the fact that all the patients had endophthalmitis due to trauma, both of which are independent risk factors for poor visual acuity. Yang et al $^{18}$ described 15 eyes of traumatic endophthalmitis that were managed either by conventional technique or open sky vitrectomy. In their series, five patients $(33 \%)$ retained useful vision at last follow up, five eyes had no light perception and had to be eviscerated. However this series had an additional risk factor for poor visual acuity, ie, retained intraocular foreign body which would explain the outcomes. Nicoara et $\mathrm{al}^{19}$ also described a series of 14 patients with traumatic endophthalmitis managed using conventional technique. Three patients in this series had opaque cornea because vitrectomy was not done and patients were treated with intraocular antibiotics (IOAB) alone. ${ }^{19}$ All three patients had poor visual outcome and ended up with legal blindness. Our study pertains to this subset of patients where in early vitrectomy circumventing the opaque media can help reduce the infection. Evisceration rates in these studies varied from 7 to $33 \%$ as compared to zero in our series. Table 2 compares the result of this study with previous larger studies.

Vitrectomy in endophthalmitis parallels a surgical principle "Pus if present must be evacuated." Early intervention by endoscopy helps in reducing the organism load, containing the infection and prevents subsequent progression to panophthalmitis. This progression, if it occurs, would decrease the likelihood of good visual outcome. ${ }^{20}$ The limitations of this study are the retrospective design, small sample size, absence of a control group, and treatment by conventional methods. In conclusion, endoscopic vitrectomy allows for early
Table 2 Comparative Outcomes of Previous Studies on Traumatic Endophthalmitis

\begin{tabular}{|l|l|l|l|}
\hline Parameter & $\begin{array}{l}\text { Yang } \\
\text { et al }\end{array}$ & $\begin{array}{l}\text { Nicoara } \\
\text { et al }{ }^{19}\end{array}$ & $\begin{array}{l}\text { Current } \\
\text { Series }\end{array}$ \\
\hline Number of eyes & 15 & 14 & 4 \\
\hline Mean age (years) & 41 & 37 & 24.5 \\
\hline Male gender (\%) & $15(100 \%)$ & $14(100 \%)$ & $2(50 \%)$ \\
\hline $\begin{array}{l}\text { Vision at presentation CFCF or } \\
\text { worse }\end{array}$ & 14 & 11 & 4 \\
\hline Final vision 20/400 or better & 5 & 11 & 3 \\
\hline Eyes with NPL & 5 & 1 & 0 \\
\hline Mean follow up (months) & 8.6 & 6.21 & 7.75 \\
\hline Culture positivity & $8(53 \%)$ & $9(64.2 \%)$ & $2(50 \%)$ \\
\hline
\end{tabular}

Abbreviations: CFCF, counting fingers close to face, NPL, no light perception.

intervention in traumatic endophthalmitis with opaque cornea as it gives access to the vitreous cavity. This allows for early settlement of infection minimizing the need for multiple interventions thus leading to good anatomic and visual outcomes.

\section{Disclosure}

The authors report no conflicts of interest in this work.

\section{References}

1. Ahmed Y, Schimel AM, Pathengay A, Colyer MH, Flynn HW Jr. Endophthalmitis following open-globe injuries. Eye (Lond). 2012;26:212-217.

2. Bhagat N, Nagori S, Zarbin M. Post-traumatic infectious endophthalmitis. Surv Ophthalmol. 2011;56:214-251. doi:10.1016/j. survophthal.2010.09.002

3. Faghihi H, Hajizadeh F, Esfahani MR, et al. Post-traumatic endophthalmitis: report no. 2. Retina. 2012;32:146-151. doi:10.1097/ IAE.0b013e3182180087

4. Long $\mathrm{C}$, Liu B, Xu C, et al. Causative organisms of post-traumatic endophthalmitis: a 20 year retrospective study. BMC Ophthalmol. 2014;14:34. doi:10.1186/1471-2415-14-34

5. Peyman GA, Carroll CP, Raichand M. Prevention and management of traumatic endophthalmitis. Ophthalmology. 1980;87:320-324. doi:10.1016/S0161-6420(80)35240-8

6. Ben-Nun J. Cornea sparing by endoscopically guided vitreoretinal surgery. Ophthalmology. 2001;108:1465-1470. doi:10.1016/S01616420(01)00642-X

7. Dave VP, Pathengay A, Behera S, et al. Enterobacter endophthalmitis: clinical settings, susceptibility profile, and management outcomes across two decades. Indian $J$ Ophthalmol. 2020;68:112-117. doi:10.4103/ijo.IJO_693_19

8. Dave VP, Joseph J, Pathengay A, Pappuru RR, Das T. Clinical presentations, diagnosis, and management outcomes of Curvularia endophthalmitis and a review of literature. Retina. 2020;40:370-375.

9. Dave VP, Joseph J, Pathengay A, Pappuru RR, Das T. Clostridial endophthalmitis: clinical presentations, management outcomes, and review of literature. Retin Cases Brief Rep. 2019. doi:10.1097/ ICB.0000000000000889 
10. Dave VP, Joseph J, Jayabhasker P, Pappuru RR, Pathengay A, Das T. Does ophthalmic-grade silicone oil possess antimicrobial properties? J Ophthalmic Inflamm Infect. 2019;9:20. doi:10.1186/s12348-0190187-6

11. Thorpe HE. Ocular endoscopy: an instrument for removal of intravitreous nonmagnetic foreign bodies. Trans Am Acad Ophthalmol. 1934;39:422-424.

12. Norris JL, Cleasby GW, Nakanishi AS, Martin LJ. Intraocular endoscopic surgery. Am J Ophthalmol. 1981;91:603-606. doi:10.1016/ 0002-9394(81)90058-1

13. Uram M. Ophthalmic laser microendoscope ciliary process ablation in the management of neovascular glaucoma. Ophthalmology. 1992;99:1823-1828. doi:10.1016/S0161-6420(92)31718-X

14. De Smet M, Ghyczy-Carlborg EAE, Mura M. Endoscopy for the management of severe endophthalmitis. Acta Ophthalmol Scand. 2004;84(Supplement 239):96-98.

15. Dave VP, Pappuru RR, Tyagi M, Pathengay A, Das T. Endoscopic vitrectomy in endophthalmitis: initial experience of 33 cases at a tertiary eye care center. Clin Ophthalmol. 2019;13:243-251. doi:10.2147/OPTH.S185716
16. Ozimek M, Nowomiejska K, Forlini C, Rejdak R. Posttraumatic endophthalmitis due to tobacco drying wire treated with vitrectomy, temporary keratoprosthesis, and keratoplasty. Ophthalmol J. 2016;1:36-39. doi:10.5603/OJ.2016.0006

17. Chun DW, Colyer MH, Wroblewski KJ. Visual and anatomic outcomes of vitrectomy with temporary keratoprosthesis or endoscopy in ocular trauma with opaque cornea. Ophthalmic Surg Lasers Imaging. 2012;43(4):302-310. doi:10.3928/15428877-20120618-09

18. Yang CS, Lu CK, Lee FL, Hsu WM, Lee YF, Lee SM. Treatment and outcome of traumatic endophthalmitis in open globe injury with retained intraocular foreign body. Ophthalmologica. 2010;224:7985. doi: $10.1159 / 000235725$

19. Nicoara SD, Irimescu I, Calinici T, et al. Outcome and prognostic factors for traumatic endophthalmitis over a 5-year period. $J$ Ophthalmol. 2014;747015.

20. Pappuru RR, Dave VP, Pathengay A. Endophthalmitis progressing to panophthalmitis: clinical features, demographic profile and factors predicting outcome. Semin Ophthalmol. 2017;19:1-4.

\section{Publish your work in this journal}

The International Medical Case Reports Journal is an international, peer-reviewed open-access journal publishing original case reports from all medical specialties. Previously unpublished medical posters are also accepted relating to any area of clinical or preclinical science. Submissions should not normally exceed 2,000 words or 4 published pages including figures, diagrams and references. The manuscript management system is completely online and includes a very quick and fair peer-review system, which is all easy to use. Visit http://www.dovepress.com/testimonials.php to read real quotes from published authors. 